\title{
TEATRALIDADE HUMANA: CLOWNIFICANDO O AMBIENTE HOSPITALAR
}

\author{
Augusto Luis Medeiros Amaral ${ }^{1}$ \\ ${ }^{1}$ Doutorando no Programa de Pós-Graduação em Educação Ambiental (PPGEA) da Universidade Federal do Rio \\ Grande - FURG. Rua Ceslau Mario Biezanko, 51 Casa 01 - CEP 96080-420 - Pelotas/RS.
}

Palavras-Chave: ecosofia, intervenção socioambiental, corpo, cartografia, experimentação.

Este artigo baseia-se em uma pesquisa-intervenção realizada em laboratório e objetiva mobilizar a capacidade intuitiva, inventiva, relacional e afetiva do humano. A contribuição metodológica aqui apresentada é embasada na oficina "Experimentações Estéticas: clownificando o ambiente hospitalar" realizada no Hospital Universitário da Universidade Federal do Rio Grande. A pesquisa, em andamento, é fundada na concepção de Educação Ambiental de Felix Guattari (As Três Ecologias), e vem indicando a necessidade de promovermos ações que fomentem a autogestão, a participação, a autonomia, bem como a capacidade de criar alternativas diante dos problemas e obstáculos. Evidencia um processo de intervenção socioambiental inspirado na metodologia sociopoética e aponta para a necessidade de criarmos estratégias que potencializem a solidariedade e tornem o humano capaz de enfrentar condicionamentos e dualidades. Isto acontece na medida em que os participantes da oficina avançam no processo de nascimento do clown, na experimentação de modos de existência inspirados em valores ético-estéticos. Indica que é necessário desconfiar dos ambientes que obstaculizam o encontro dos corpos, que reduzam o tato, o contato, a interação dos corpos. Ao colocar o corpo como objeto de análise é preciso avançar com relação a uma abordagem mais ampla, interdisciplinar e multiprofissional, este tem sido o desafio do projeto de extensão "Raiz do Riso", no qual se insere esta pesquisa.

\section{Intervenções socioambientais em laboratório}

Este artigo é embasado em uma intervenção socioambiental em laboratório realizada ao longo do curso de doutorado, no Programa de Pós-Graduação em Educação Ambiental (PPGEA) da Universidade Federal do Rio Grande - FURG. A pesquisa-intervenção ${ }^{2}$, em andamento, objetiva problematizar algumas das temáticas colocadas como desafio para o campo da Educação Ambiental: a necessidade de melhorar a qualidade de vida, de trabalhar solidariamente, de romper com a alienação, e, sobretudo, de aprendermos a lutar pela vida, estão entre elas.

\footnotetext{
2 A pesquisa-intervenção, de certa forma, provoca rupturas nas perspectivas colocadas pelo movimento da Pesquisa-Ação, principalmente naquelas perspectivas referentes às relações entre teoria e prática, entre sujeito e objeto, na medida em que coloca para o pesquisador a noção de implicação como desafio. No projeto da Pesquisa-Ação, contraponto radical ao positivismo na defesa de uma teoria amalgamada na ação comprometida do pesquisador, a busca de dados inclui testemunhos, associa entrevistas, questionários, análise de conteúdo e restituição das informações aos pesquisados. Visa, muitas vezes, à tomada de consciência, a mudanças de comportamento.
} 
No laboratório de pesquisa, onde acontecem as oficinas, são desenvolvidas experimentações objetivando desencadear uma espécie de estranha inquietude nos participantes. Importante elemento na tentativa de produzir outra perspectiva de vida, despertando o desejo de entrarmos em contato com nossa força e coragem, com a vontade de transformar o ambiente, os outros, e a nós mesmos. Este é o trabalho de campo de um pesquisador atento às trajetórias que se tramam com seu próprio percurso, disposto a lidar com o paradoxo de ocupar a posição de sujeito e objeto da pesquisa.

O conceito da Teatralidade Humana, que estou desenvolvendo no doutorado como arcabouço teórico das experimentações, se enraíza no entrecruzamento da experiência empírica e do pensamento reflexivo. Constitui-se toda vez que leio, ouço e debato no campo do conhecimento, que confronto ideias e fatos, toda vez que meu pensamento é provocado, que coloco o corpo em movimento no fluxo de dilemas e questões socioambientais. O conceito, de natureza sociológica, flui no encontro com a simplicidade, quando se flexiona uma linguagem carregada de sentidos, saberes e paixões. Ele é fruto do desejo, daquilo que se quer em demasia (NIETZSCHE, 2006).

Trata-se de uma cartografia (GUATTARI e ROLNIK, 1996) dos limites e possibilidades da ação humana - dos deslocamentos efetivados no tempo e no espaço, um mapa dos movimentos realizados pelos corpos enquanto transformam o ambiente em que estão inseridos. Uma cartografia das buscas, das tentativas, de erros e acertos, da produção de modos de vida inspirados em valores ético-estéticos (GUATTARI, 1990). Uma pesquisa fundada na concepção de Educação Ambiental de Felix Guattari (As Três Ecologias), que se volta para as dimensões intensivas do humano.

Este artigo apresenta um momento específico do processo de intervenção socioambiental onde os corpos dos participantes da oficina são colocados em movimento pelas experimentações da Teatralidade Humana. Entendo o corpo como lugar de onde emerge e se perpetua o próprio teatro. O corpo é teatral, todos nós somos teatrais, e isso se torna cada vez mais palpável na medida em que conduzimos a vida, em nosso cotidiano, como um acontecimento único, peculiar. A Teatralidade Humana se aproxima do conceito Estética da Existência (FOUCAULT, 1985 e 2004) toda vez que indica a elaboração da vida, no cotidiano das pessoas comuns (incluindo os artistas), como autêntica expressão artística: a vida como obra de arte.

Minha compreensão de teatro diz respeito ao encontro humano, onde quer que ele aconteça, pressupondo conflitos, partilhas, disputas, intercâmbio. Implica participação direta, ação, movimento corporal, enfim, distribuição do poder de atuar entre atores e não atores. A Teatralidade Humana defende um teatro que seja capaz de promover a reinvenção dos corpos, permitindo o surgimento do novo e a transformação do meio ambiente. Isto implica certa diluição das fronteiras existentes entre o palco teatral e o grande palco da vida.

As intervenções socioambientais têm o objetivo de fazer surgir modos de existência mais conectados com as forças da vida, onde cultura e natureza deixam de ser vistas como coisas separadas, e o corpo humano é compreendido como fruto de um complexo processo de interação com o meio - transformando e sendo transformado pelo ambiente em que está inserido.

Trata-se de um esforço na tentativa de restaurar a dimensão artística do processo de aprendizagem, estimulando a criatividade e a capacidade de interação dos corpos no ambiente, potencializando diversas formas de expressão humana, ativando as esferas intuitivas, inventivas, afetivas do humano. 


\section{Monografias Ambientais e-ISSN: 2236-1308}

Ao colocar o corpo como objeto de análise é preciso avançar com relação a uma abordagem mais ampla, transdisciplinar e multiprofissional ${ }^{3}$, este tem sido o desafio do projeto de extensão "Raiz do Riso: clown criando espaços de saúde e suas poções mágicas", no qual se insere esta pesquisa.

\section{Os ambientes estriados e o controle dos corpos}

A pesquisa se inspira na metodologia sociopoética (GAUTHIER, 2009) e é desenvolvida a partir dos processos de diferenciação da comunidade pesquisadora ${ }^{5}$, enquanto estabelecemos diálogos possíveis entre as diferentes áreas do conhecimento. A pesquisa está sendo organizada a partir dos depoimentos de participantes da oficina, dos e-mails trocados entre os pesquisadores, das fotos e filmagens realizadas durantes as intervenções socioambientais, de anotações no diário de itinerância ${ }^{6}$ e de gravações dos encontros da comunidade pesquisadora.

A sociopoética defende os laços de dependência mútua entre o que é chamado de objeto e de sujeito da pesquisa, pressupondo a inserção de variadas formas de racionalidade e a possibilidade de que outras fontes de conhecimento, não racionais e sim emocionais, sensíveis, imaginativas e motrizes, entrem em jogo na organização da pesquisa e na intervenção propriamente dita. Isso fica evidente toda vez que os talentos individuais conseguem se agregar em torno de uma corporeidade multíplice: expressão de uma coletividade em ação. É quando as metamorfoses acontecem, seus efeitos têm visibilidade, sua intensidade transforma ambientes e impulsiona outros corpos.

O humano é corpo difícil de distinguir os limites, as vizinhanças, onde começam e terminam suas interconexões, pois está permanentemente trocando, recebendo e transmitindo informações, energia, calor, produzindo e reproduzindo, ensinando e aprendendo. A Teatralidade Humana é sensível aos corpos que se redefinem quando transitam, intensificam intercâmbios, relacionam-se, comunicam-se, aos corpos que ousam sabotar os dispositivos de controle instituídos.

Vivemos um momento de transição entre a Sociedade Disciplinar (FOUCAULT, 2009) e a Sociedade de Controle (DELEUZE, 1992), em que se difunde amplamente o controle incessante em meio aberto. Neste momento os dispositivos de controle se sofisticam para que seja garantido o comportamento normal das massas. Há um processo de instauração da lógica do confinamento,

\footnotetext{
${ }^{3}$ A pesquisa-intervenção é realizada por uma coletividade acadêmica, envolvendo uma estudante do curso de Ciências Contábeis da Universidade Federal do Rio Grande (FURG), uma estudante do curso de Psicologia da FURG, bem como um sociólogo, uma enfermeira e um arte-educador, doutorandos do Programa de Pós-Graduação em Educação Ambiental (PPGEA) da FURG.

${ }^{4} \mathrm{O}$ "Raiz do Riso: clown criando espaços de saúde e suas poções mágicas" é um projeto de extensão da Universidade Federal do Rio Grande (FURG), vinculado ao Instituto de Ciências Econômicas, Administrativas e Contábeis (ICEAC), e coordenado pelo prof. Dr. Alfredo Guillermo Martin Gentini (martingen@ibest.com.br).

${ }^{5}$ A instituição da comunidade pesquisadora como autora da pesquisa é um aspecto essencial da proposta de intervenção socioambiental. A comunidade pesquisadora é uma coletividade multiprofissional que, neste momento (outubro de 2011), é formada por um sociólogo (Augusto Amaral), uma enfermeira (Aline Oliveira) e um arte-educador (Cláudio Azevedo), todos doutorandos no curso de Pós-Graduação em Educação Ambiental (FURG/PPGEA). Segundo Gauthier, "não se trata de um grupo que pesquisa, mas de um ser coletivo, que se institui no início da pesquisa como grupo-sujeito do seu devir" (GAUTHIER, 2009, p.17).

${ }^{6}$ Este é “o diário institucional, que René Barbier (2006) chama com felicidade de 'diário de itinerância', ou seja, de caminho onde podemos nos perder e nos re-encontrar. É bom propor um grande caderno onde todos e todas, inclusive os facilitadores, podem escrever, colar, desenhar" (GAUTHIER, 2009, p.12).
} 


\section{AMARAL, vol.(5), n`5, p. $1199-1204,2012$.

em toda a sociedade, sem que seja necessária a existência de muros que separem o lado de dentro das instituições do seu exterior.

$\mathrm{Na}$ Sociedade Disciplinar, dominava o modelo do panóptico, implicando que o vigia estivesse presente em tempo real. Na Sociedade de Controle a vigilância é introjetada no humano, se torna rarefeita, pulverizava. Com a sofisticação tecnológica e com a proliferação dos mecanismos de controle, os indivíduos passam a ser muito mais eficientemente governados. Câmeras de vigilância e microfones se espalham pelas ruas, casas, praças, prédios e becos.

A paisagem da cidade mostra um ambiente estriado, que só se sustenta pela força coercitiva (estatal e privada), em nome da ordem e dos costumes. Mas de fato, quem se beneficia com isto? Embora o esquadrinhamento minucioso do espaço possa gerar algum conforto e segurança, será que produz resultados efetivamente práticos que se estendam a todas as camadas da população? E quais os desdobramentos desse processo no que tange as demais formas de vida sobre o planeta? As estatísticas, dados científicos e informações oficiais mostram que, de fato, estamos muito longe de resolver os problemas socioambientais.

O ambiente urbano, com seu excedente de linhas retas, submete o humano a um elevado grau de controle e previsibilidade, impondo o regime da sobre-codificação, da constância, da monotonia, da normalidade, propagando movimentos corporais que se repetem indefinidamente. Vivemos um sedentarismo muito mais amplo e perigoso do que imaginamos. Aderimos ao estilo de vida urbano com a certeza de que estamos sendo protegidos pela rotina de uma vida aparentemente estável.

\section{O clown como possibilidade de intervenção socioambiental}

A contribuição metodológica deste artigo é embasada na oficina "Experimentações Estéticas: clownificando o ambiente hospitalar" realizada em 14 de maio de 2011, no Hospital Universitário da Universidade Federal do Rio Grande (FURG), durante a 35a Semana Riograndina de Enfermagem da FURG.

A oficina, de caráter intervencionista, coordenada pelos doutorandos em Educação Ambiental (PPGEA/FURG) Augusto Amaral e Cláudio Azevedo, objetivou impulsionar o processo de nascimento do clown dos participantes. Os primeiros resultados da pesquisa apontam para 0 nascimento do clown como força de resistência aos processos sedentários e de estagnação da vida. Isto acontece porque o clown gera ondas de instabilidade toda vez que quebra barreiras impostas por palcos e picadeiros, criando micro fissuras nos ambientes instituídos, rompendo os limites entre a vida e a arte.

0 processo de nascimento do clown desdobra-se em um tipo de perturbação à normalidade, à estabilidade dos ambientes controlados, aos poderes instituídos com seus códigos de conduta, normas, hábitos, leis e regras sociais. Coloca em dúvida a legitimidade dos valores perpetuados pela tradição, através do exercício de desnaturalização das instituições.

Os resultados preliminares mostram que o palhaço consegue transitar com leveza e espontaneidade em lugares adversos como hospitais, asilos, espaços psiquiátricas, etc. Ele não conta com a proteção do espaço cênico porque se envolve completamente, se expõe por inteiro, desnuda-se. É livre porque inventa permanentemente entrelugares. Sua principal virtude é fazer brotar a liberdade da invenção e do pensamento. Entrega-se a si mesmo e à relação com o público, relaciona-se ativamente com o ambiente onde atua. 


\section{AMARAL, vol.(5), n5, p. 1199 - 1204, 2012. Monografias Ambientais e-ISSN: 2236-1308}

A questão da liberdade é uma das temáticas que impulsiona a Teatralidade Humana, funciona como uma inesgotável fonte de problematização que nutre a pesquisa. Precisa ser aprofunda para se tornar capaz de subsidiar as reflexões em torno da autonomia, da espontaneidade, da solidariedade e dos processos autogestivos. Questões centrais na tentativa de colocar o pensamento em movimento, como autêntica máquina de guerra nômade ${ }^{7}$.

O nariz do clown é uma máscara que ao invés de esconder o ridículo do humano, mostra nossas atrapalhações e imperfeições. Uma diminuta máscara que coloca em movimento certas energias que estão estagnadas no cotidiano da vida urbana. Faz fluir o mesmo tipo de energia que está presente nos córregos e florestas, com sua variedade de formas, traços sinuosos, múltiplas gradações. A energia e a beleza do clown se identificam com as matas ciliares e nascentes dos rios. O caos e a desordem não são problemas para ele, pois os considera matéria-prima de seus processos de criação ativa.

Experimentar o clown talvez seja uma maneira de restituirmos nossa capacidade de lidar com as explosões caóticas da vida, seus descompassos e desequilíbrios. Aprofundar a pesquisa com o clown implica avançar tanto do ponto de vista da educação e da formação quanto da saúde humana. Lidar criativamente com o corpo e suas vertigens pode nos dar um novo entendimento a respeito da saúde e da doença, da loucura e da lucidez, da vida e da morte.

A comunidade pesquisadora prepara-se, a cada nova oficina, para tentar atuar nos três registros ecológicos - o meio ambiente, as relações sociais e a subjetividade humana - conforme preconiza a Ecosofia (GUATTARI, 1990). O trabalho de campo desdobra-se em experimentação estético-ambiental toda vez que as intervenções vão ao encontro da concepção nietzscheana de grande saúde (2000, 2001, 2006), ampliando e diversificando seus espaços de atuação - as próximas intervenções previstas serão realizadas no CAPS e no Hospital Psiquiátrico, em Rio Grande.

A medicina moderna ${ }^{8}$ vem agregando ao seu universo alternativas que levam em consideração aspectos psicossociais do enfermo: histórico de vida, percepção de realidade, relacionamentos, condição social, vida profissional e familiar, hábitos e costumes. Todo esse empreendimento científico converge em extirpar a doença ou eliminar a deficiência, a fim de devolver ao paciente sua condição normal.

Desse ponto de vista, indago se este quadro referencial, que define o que seja uma pessoa normal, não poderia induzir, não somente médicos, mas também profissionais de outros campos do saber, como a educação, por exemplo, ao enquadramento em um perfil padrão, em um modelo idealizado do humano, determinando o que seja corpo e mente saudável, ou melhor, dentro dos padrões de normalidade ${ }^{9}$.

\footnotetext{
${ }^{7}$ Deleuze e Guattari diferenciam o espaço nômade do espaço sedentário e falam da ação da máquina de guerra nômade: "o espaço sedentário é estriado, por muros, cercados e caminhos entre os cercados, enquanto o espaço nômade é liso, marcado apenas por 'traços' que se apagam e se deslocam com o trajeto. (...) E cada vez que há uma operação contra o Estado, indisciplina, motim, guerrilha ou revolução enquanto ato, dir-se-ia que uma máquina de guerra ressuscita, que um novo potencial nomádico aparece, com reconstituição de um espaço liso ou de uma maneira de estar no espaço como se fosse liso" (DELEUZE e GUATTARI, 1997, p.51 e 60).

${ }^{8}$ Sobre a emergência da medicina moderna como prática normalizadora de caráter coletivo ver: Foucault, Michel. Microfísica do Poder. (1999).

${ }^{9}$ A norma constitui uma categoria central para a compreensão do que Foucault denominou como biopoder, estratégia de governo analisada pelo autor em sua História da Sexualidade, que tem sua emergência no interior de novas formas de administração das políticas internas e externas voltadas para a vida das populações nos séculos XVII, XVIII e XIX. Nesse sentido, a normalidade é "um
} 


\section{AMARAL, vol.(5), n5, p. $1199-1204,2012$.

O trabalho de experimentação cumpre suas metas fundamentais quando atua em certas regiões fronteiriças, entre palco e platéia, entre ator e espectador, entre ambiente teatral e ambiente cotidiano (ARTAUD, 1999), instigando um pensamento que só pode ser colocado em movimento pelas necessidades inadiáveis, materializadas, evidentes. A criação de novos conceitos, na perspectiva da Teatralidade Humana, tem que ser impulsionada pelo que é imediato, pulsante, vivenciado. Teatralizar implica agir, pensar, transformar, desterritorializar, criar outros mundos por intermédio de fazeres com inspiração artístico-pedagógica.

A análise aqui proposta vai ao encontro de ações que potencializem o corpo tornando-o capaz de se expressar e superar condicionamentos. Está atenta aos processos de experimentação que procuram desenvolver a habilidade humana de se vincular com outros corpos e de viabilizar soluções auto-gestivas frente às demandas e contingências da vida. Questiona ambientes e práticas que depreciam a vida e desconfia de tudo aquilo que despreza o corpo, colocando em dúvida os ambientes que impedem o encontro dos corpos, que reduzam o tato, o contato, a interação humana. Entende que precisamos estar atentos, sobretudo, aos modelos instituídos de acordo com os interesses do grande capital.

\section{Referências}

ARTAUD, Antonin. O Teatro e seu Duplo. 2. ed. São Paulo: Martins Fontes, 1999. BARBIER, René. A pesquisa-ação. Brasília: LiberLivro, 2006.

DELEUZE, Gilles. Conversações. Rio de janeiro. Editora 34, 1992.

DELEUZE, Gilles e GUATTARI, Félix. Mil Platôs - capitalismo e esquizofrenia, vol. 5. São Paulo: Editora 34, 1997.

FOUCAULT, Michel. Ética, Sexualidade, Política (Ditos \& Escritos). Rio de Janeiro: Forense Universitária, 2004.

. História da Sexualidade III: O cuidado de si. São Paulo, Edições Graal, 1985.

. Microfísica do Poder. 14a Ed. Rio Janeiro: Graal, 1999.

. Vigiar e Punir: nascimento da prisão. 36. ed. Petrópolis,RJ: Vozes, 2009.

GAUTHIER, Jacques. Sociopoética: o livro do iniciante e do orientador. Edição Eletrônica. 2009.

GUATTARI, Félix. As Três Ecologias. Campinas, SP: Papirus, 1990.

GUATTARI, Felix e ROLNIK, Suely. Micropolítica: cartografias do desejo. Petrópolis, RJ: Vozes, 1996.

NIETZSCHE, Frederich Wilhelm. A gaia ciência. Tradução Paulo César Souza. São Paulo: Cia. das Letras, 2001.

. Humano, Demasiado Humano. São Paulo: Escala, 2006.

. Nietzsche contra Wagner. Tradução Paulo César Souza. São Paulo: Cia. das Letras, 2000.

RAJCHMAN, John. Eros e Verdade: Lacan, Foucault e a questão da ética. Rio de Janeiro: Jorge Zahar, 1993.

modo de nos identificar e de fazer com que nos identificássemos de maneira a nos tornarmos governáveis" (RAJCHMAN, 1993, p. 122). 